\title{
Sistem Pengukur Curah Hujan Sebagai Deteksi Dini Kekeringan Pada Pertanian Berbasis Internet of
}

\author{
Things \\ Satrio S. Laksono ${ }^{1}$, Nurgiyatna ${ }^{2}$ \\ Program Studi Informatika \\ Universitas Muhammadiyah Surakarta \\ Surakarta, Indonesia \\ Email: ${ }^{1}$ fitkuu@gmail.com, ${ }^{2}$ nurgiyatna@ums.ac.id
}

\begin{abstract}
Abstraksi-Hujan merupakan faktor penting dalam segala aspek kehidupan, tidak tentunya kedatangan hujan saat ini sangat berpengaruh terhadap kegiatan industri, terutama pada sektor pertanian. Dalam industri pertanian tinggi rendahnya curah hujan sangat berpengaruh dalam pengelolaan sumber daya dan juga sangat menentukan hasil panen yang akan didapati. Sebagai contoh curah hujan yang terlalu tinggi dapat menyebabkan gagal panen dikarenakan resiko terjadinya banjir yang membuat tanaman padi mati, begitu pula curah hujan yang terlalu sedikit dapat pula menyebabkan gagal panen dikarenakan kurangnya sumber air. Dengan adanya Inernet of Things (IoT) dan Social Media diharapkan dapat membantu para petani dalam mengelola sumber air untuk lahan pertanian mereka. Penelitian ini menggunakan metode eskperimental dengan percobaan langsung terhadap hujan. Raspberry pi 3 digunakan sebagai controller, sensor magnetik diterapkan sebagai pengukur curah hujan yang dihubungkan memalui interface GPIO pada raspberry pi 3, dan diteruskan pada API (Application Programming Interface) Telegram berupa bot sebagai sebuah pesan. Tampilan pengontrol berupa sebuah layar chat yang terdapat pada telegram yang dapat digunakan untuk mengirim perintah yang sudah disediakan.
\end{abstract}

Kata Kunci-Hujan, pertanian, raspberry pi3, internet of things, telegram, API, social media

Abstracts- Rain is an important factor in all aspects of life, it is not certain that the arrival of rain is currently very influential on industrial activities, especially in the agricultural sector. In the agricultural industry high and low rainfall is very influential in the management of resources and also determines the yield that will be found. For example, too high rainfall can cause crop failure due to the risk of flooding that causes rice plants to die, as well as too little rainfall can also cause crop failure due to lack of water sources. With the existence of the Internet of Things (IoT) and Social Media, it is expected to be able to help farmers in managing water sources for their agricultural land. This study uses experimental methods with direct experiments on rain. Raspberry pi 3 is used as a controller, magnetic sensors are applied as a rainfall gauge connected to the GPIO interface on raspberry pi 3, and forwarded to the Telegram API (Application Programming Interface) in the form of a bot as a message. The controller display is a chat screen found on the telegram that can be used to send commands that have been provided.

Keywords - Rain, agriculture, raspberry pi3, internet of things, telegram, API, social media

\section{PENDAHULUAN}

Hujan merupakan faktor penting dalam segala aspek kehidupan, tidak tentunya kedatangan hujan saat ini sangat berpengaruh terhadap kegiatan industri, terutama pada sektor pertanian. Perubahan musim yang tidak menentu di Indonesia menyebabkan sulitnya pengelolaan lahan. Menurut Hidayati dan Suryanto [1] berkurangnya intensitas hujan adalah alasan terbesar dari penurunan hasil panen petani di lahan kering di Dharmaputri, India. Penurunan hasil panen tersebut menyebabkan penurunan pendapatan para petani. Penurunan pendapatan petani tersebut merupakan dampak jangka pendek, sedangkan dampak jangka panjangnya adalah berakhirnya profesi petani lahan kering (off-farm employment). Maka dari itu banyak upaya yang dilakukan untuk mempermudah perencanaan pengelolaan lahan pertanian. Salah satunya adalah menggunakan Internet of Things (IoT).

Menurut Ullah [2] Internet of Things adalah infrastruktur di seluruh dunia yang akan menghubungkan objek virtual dan fisik, mengabaikan jarak di antara mereka, berdasarkan eksploitasi data dan kemampuan routing. Melihat kegunaan bot yang dapat membantu pekerjaan dan aktivitas harian manusia, menemukan informasi serta mengumpulkan informasi, Telegram membuat sebuah bot yang diberi nama Bot Telegram. Bot Telegram merupakan sebuah bot yang saat ini mulai populer digunakan dikalangan masyarakat seiring dengan maraknya messenger Telegram yang mulai diinstall banyak orang dan dipergunakan untuk percakapan sehari-hari. Aplikasi Telegram dipilih karena aplikasi ini gratis, ringan dan multiplatform. Telegram juga memiliki bot API (Application Programing Interface) yang cukup lengkap dan makin berkembang, sehingga memungkinkan untuk membuat bot pintar yang dapat merespon pesan dari masyarakat [3].

Berdasarkan permasalahan tersebut penulis menginginkan penelitian dengan menggabungkan konsep IoT yang diterapkan 
pada sebuah Micro Computer dan melalui bot API Telegram sebagai media transmisinya untuk membuat sebuah "Sistem Pengukur Curah Hujan sebagai Deteksi Dini Kekeringan pada Pertanian Berbasis Internet of Things". Salah satu jenis alat ukur curah hujan otomatis yaitu tipe tipping bucket. Tipping bucket rain gauge merupakan alat penakar hujan yang menggunakan prinsip menimbang berat air hujan yang tertampung menggunakan bucket atau ember kemudian disalurkan dengan sebuah skala ukur (pias) yang telah ditetapkan berdasarkan pengujian dan kalibrasi [4], [5]. Pengujian dan kalibrasi untuk penakar hujan pada hakekatnya mencari fitur yang ada di dalamnya. Seperti halnya pengenalan individu, dapat diterapkan dengan mengenal data dari beragam fitur seperti sidik jari, wajah, dan telapak tangan. Untuk pengenalan dari rajah tapak tangan dapat lebih lanjut dilihat dari artikel berikut [6]-[11].

Dalam penelitian ini penulis menggunakan Raspberry pi 3 sebagai controller. Bahasa pemrograman python digunakan untuk mengambil data dari sensor kemudian mengolahnya dan diteruskan melalui API telegram sebagai sebuah pesan. Sensor yang digunakan penulis adalah sensor magnetic yang diterapkan dalam bentuk tipping bucket untuk membaca pengukuran curah hujan. Dengan menggunakan sebuah social media berupa Telegram, penulis berharap dapat memudahkan masyarakat dalam pengelolaan pertanian.

\section{METODE PENELITIAN}

Metodologi penelitian ini adalah eksperimental dengan percobaan pengukuran langsung pada hujan. Terdapat beberapa tahapan dari pembuatan sistem ini seperti analisa kebutuhan, perancangan Hardware dan Software, pembuatan Hardware dan Software, dan pengujian sistem seperti pada Gambar 1.

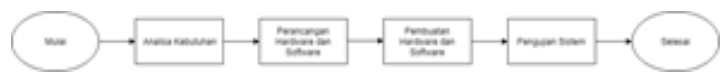

Gambar 1

\section{A. Analisa Kebutuhan}

Tahap pertama dalam penelitian ini mengumpulkan kebutuhan yang digunakan sebagai pendukung dalam melakukan penelitian. Terdapat 2 jenis kebutuhan, yaitu kebutuhan hardware, dan kebutuhan software seperti yang ditampilkan pada Tabel I.

Tabel I. Analisis kebutuhan

\begin{tabular}{ll}
\hline Perangkat Keras & Perangkat Lunak \\
\hline Laptop Intel Core i7-7700HQ RAM 8GB & SSH \\
SSD 128GB HDD 1TB VGA GTX 1050 & \\
2GB & \\
Raspberry Pi 3 model B quad core 64bit arm & Putty \\
cortex A53 1.2Ghz RAM 1GB LPDDR2 & \\
Power Supply 5V/2A & Wifi Network \\
MicroSD 8GB & CorelDRAW X7 \\
GPIO extension board & Telegram App \\
Sensor Curah hujan & Sublime Text \\
Kabel LAN & Telegram Bot API \\
Kabel Jumper & Python 3 \\
Breadboard & Thingspeak \\
Acrylic Case & \\
\hline
\end{tabular}

\section{B. Perancangan Hardware dan Software}

Pada tahap ini dilakukan perancangan dari Hardware dan Software sebelum dilakukan proses pembuatan alat. Tahapan yang dilakukan antara lain: Perancangan Hardware. Sistem Pengukur Curah Hujan terdiri dari beberapa rangkaian Hardware yaitu Power Supply, Raspberry Pi 3, dan rangkaian magnetic sensor yang digunakan sebagai sensor penghitung curah hujan. Dalam sensor terdapat 3 pin yaitu $5 \mathrm{~V}$, ground, dan output pulse yang akan dikoneksikan pada raspberry pi 3. Output pulse disini berupa digital pulse, output pulse dikoneksikan pada pin GPIO 23 untuk pin $5 \mathrm{~V}$ dikoneksikan pada pin $5 \mathrm{~V}$ raspberry pi 3 dan untuk ground dikoneksikan pada pin ground raspberry pi 3 serta power supply dikoneksikan pada port usb di raspberry pi 3. Untuk lebih jelasnya dapat diliat seperti diagram arsitektur pada Gambar 2. Pada Gambar 3 dijelaskan

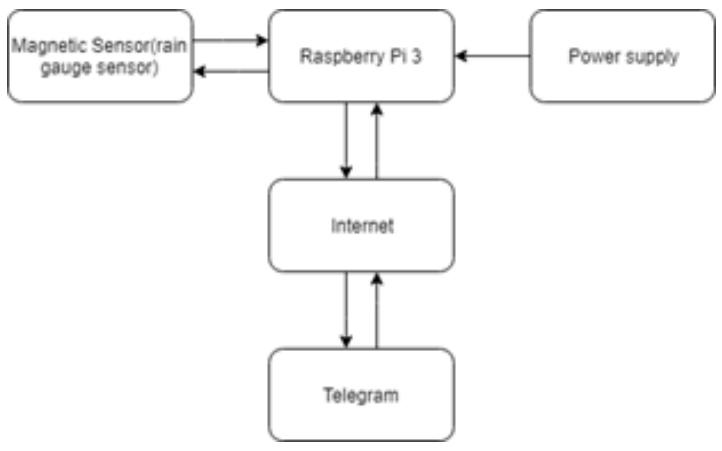

Gambar 2. Diagram arsitektur

bentuk dari rangkaian sensor hujan yang berbentuk tipping bucket. Tabel II menunjukkan pin yang akan dipakai untuk

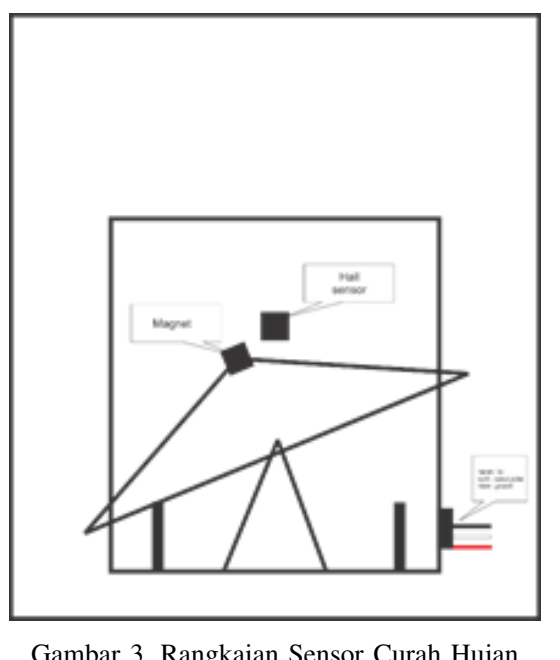

menghubungan antara raspberry pi 3 dan sensor curah hujan. Pada Gambar 4 terdapat penjelasan flowchart dari sistem yang

Tabel II. Pin koneksi

\begin{tabular}{ll}
\hline Raspberry Pi 3 & Rain Gauge Sensor \\
\hline PIN 2 (5V) & PIN 1 (VCC) \\
PIN 6 (GND) & PIN 2 (GND) \\
PIN 16 (GPIO 23) & PIN 3 (Output Pulse) \\
\hline
\end{tabular}

akan dibuat. 


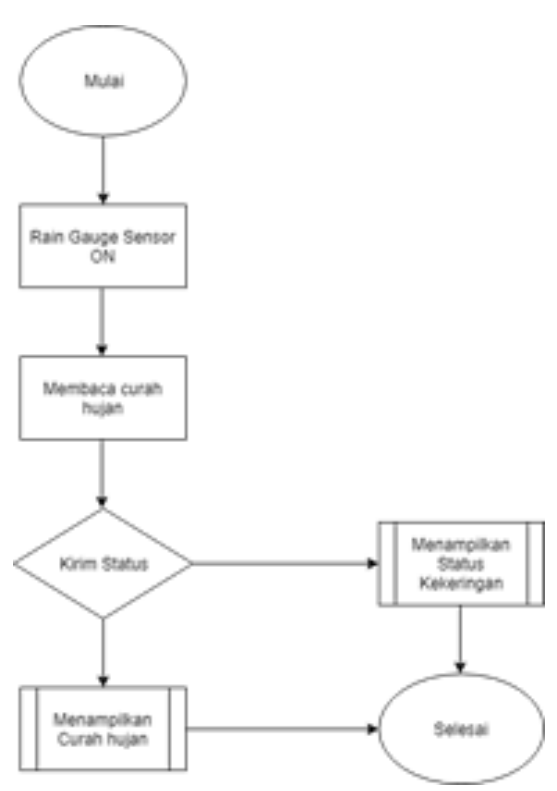

Gambar 4. Flowchart sistem

Perancangan Software. Dalam perancangan software terdapat beberapa tahapan, yaitu pembuatan bot telegram, pengkoneksian python pada bot telegram, dan pembuatan program pada python untuk inisialisasi sensor. Menurut Adawadkar [5] python itu cepat dan poweful, python mempunyai library bawaan yang menyediakan semua fasilitas yang diperlukan untuk pemrograman dari operasi dasar hingga lanjutan. Tahapan pertama perancangan software dimulai dari pembuatan bot telegram. Bot telegram di sini dibuat menggunakan BotFather yang terdapat pada aplikasi telegram. Untuk lebih jelasnya bias dilihat pada Gambar 5. Setelah bot telegram dibuat makan akan

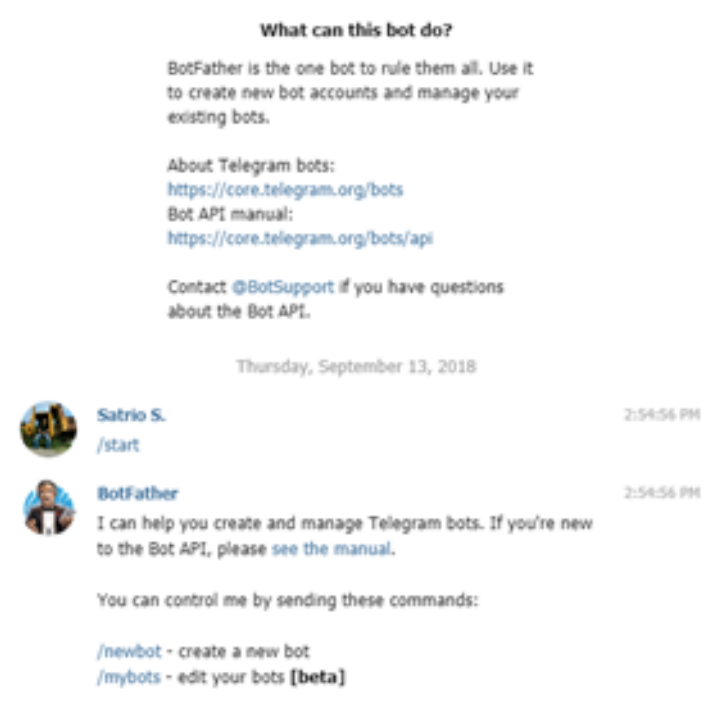

Gambar 5. Pembuatan bot telegram

didapat kode unik ( kode token ) yang akan digunakan untuk mengakses API dari bot telegram seperti terlihat pada Gambar 6. Kemudian buat program python agar dapat terkoneksi pada API telegram dan buat inisialisasi sensor pada program python yang dapat dilihat pada Gambar 7 dan Gambar 8. Flowchart
Satrio 5 .

tempTSEOT

Botfather

Donet Congratulabons on your new bot. You will find $\mathrm{k}$ at

t.me/tempTSBOT, You can now add a descrigbion, about section and profile picture for your bot, see /help for a list of commands. Oy the way, when youlve finished creating your cool bot, ping our Bot Support if you want a better username for it. Just make sure the bot is fully operabonal before you do this.

Use this token to access the HTTP API:

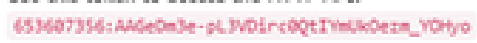

For a description of the Bot APL, see this page:

hatps://core.telegram.org/bots/api

Gambar 6. Kode Token API Telegram

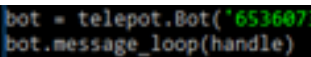

Gambar 7. Koneksi Python pada API Telegram

Channel -23

GPIO. setwode(GPIO.BCM)

coto. setup (channel, GPIO. IN)

Gambar 8. Inisialisasi Sensor pada Port GPIO

untuk perancangan software terdiri dari beberapa fungsi yang dapat dilihat pada Gambar 9.

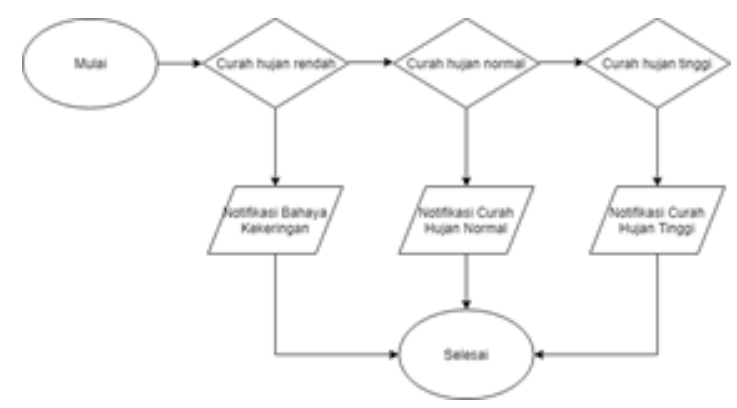

Gambar 9. Flowchart Perancangan pada Program

Pembuatan Hardware dan Software. Dalam pembuatan hardware dan software dibagi menjadi beberapa bagian yaitu :

1) Pemasangan Sensor. Pada tahap pemasangan sensor penulis merakit bagian - bagian dari sensor dan mengkoneksikannya pada raspberry pi 3, serta pengecekan dilakukan apakah sensor sudah terdeteksi dengan baik atau belum. Bentuk sensor dapat dilihat pada Gambar 10.

2) Pembuatan Fungsi pada Program. Tahap pembuatan fungsi adalah tahap dimana semua fungsi yang dibutuhkan untuk menjalakan aplikasi dibuat. Fungsi - fungsi ini akan dimasukkan ke dalam program dengan Bahasa python seperti terlihat pada Gambar 11.

3) Desain tampilan. Pada tahap ini penulis menggunakan tampilan pada aplikasi telegram dengan beberapa command yang sudah diatur dalam bot telegram. Untuk lebih jelasnya dapat dilihat pada flowchart Gambar 12.

4) Pengujian Sistem. Tahap ini dilakukan untuk menguji sistem sudah sesuai dengan diagram alur yang telah dibuat, dengan cara menguji perangkat keras dan lunak sudahkah sesuai dengan fungsi masing-masing. Pengujian hardware 


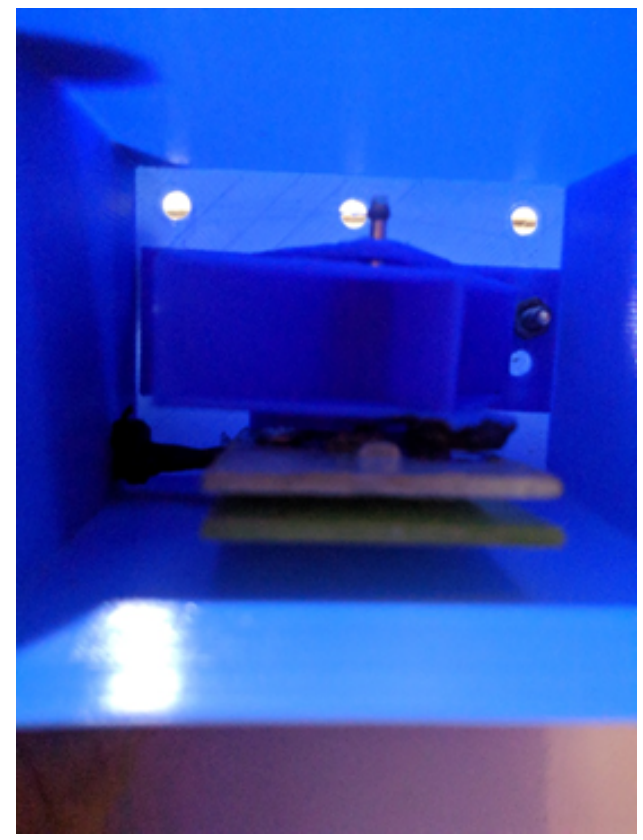

Gambar 10. Bentuk Sensor Pengukur Curah Hujan

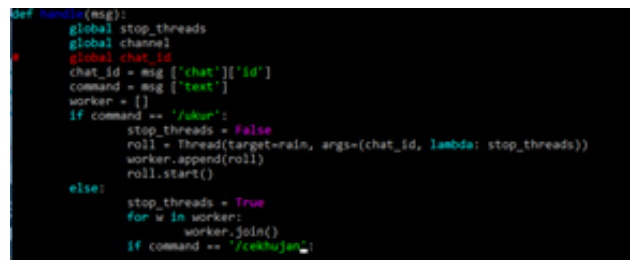

Gambar 11. Fungsi pada Program Python

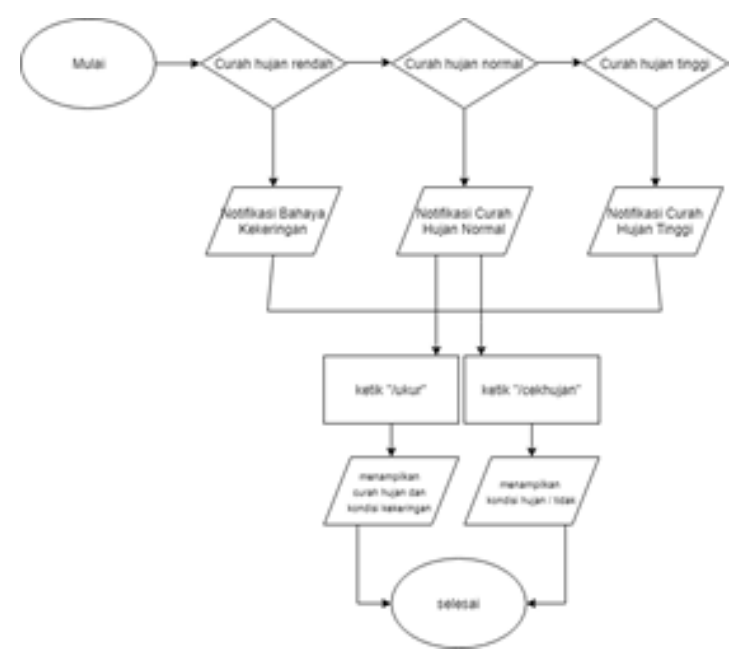

Gambar 12. Flowchart interface

dilakukan dengan cara pengecekan semua koneksi hardware yang terhubung antar perangkat, dan mengakses bot telegram melalui Internet untuk membuka testing fungsi pada program yang dibuat.

\section{HASIL DAN PEMBAHASAN}

Hasil dari penelitian yang dibuat adalah sebuah rangkaian Embedded System yang dapat dilihat pada Gambar 13, rangkaian pada gamabr terdiri dari Raspberry Pi 3, Magnetic Sensor yang telah dimodifikasi menjadi Rain Gauge Sensor, MicroSD 8GB, konektor GPIO, dan beberapa kabel untuk menghubungkan Raspberry Pi 3 ke Rain Gauge Sensor. Pada Raspberry Pi 3 terdapat serangkaian code berbahasa Python yang terkoneksi pada API telegram, terkoneksi dengan jaringan internet dan dapat diakses dimana saja melalui aplikasi telegram.

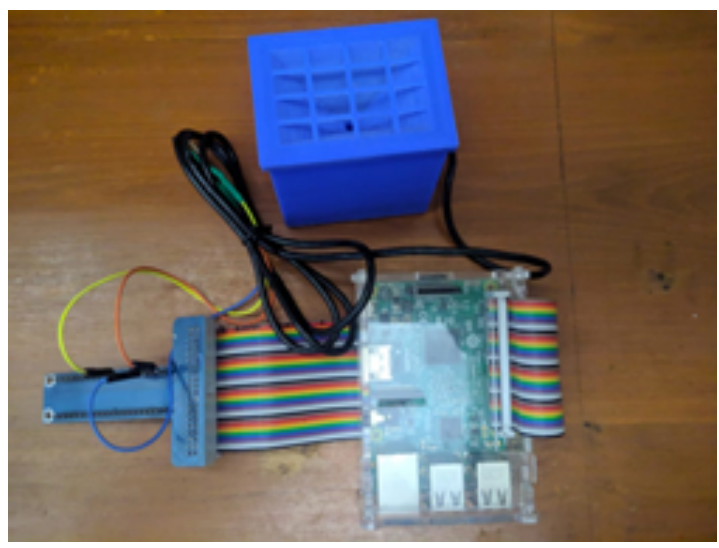

Gambar 13. Rangkaian Sistem Pengukur Curah Hujan

Pada tabel III dilakukan pengujian dengan memberi variable TRUE pada sensor dengan 10 kali percobaan, acuan dalam penghitungan sensor didapat dengan menghitung tiap tip pada sensor, tip sensor bernilai $2.6 \mathrm{~mL}$. Luas rain collector adalah 3.012 inci $^{2}$, dalam sistem satuan United States 1 inci $^{2}=1 \mathrm{inch}^{3}$, 3.012 inci $^{3}$ dikonversi menjadi $49.358 \mathrm{~mL}$ sehingga 1 inci hujan $=49.385 \mathrm{~mL}$ dan 1 tip sensor mewakili $2.6 \mathrm{~mL} / 49.358 \mathrm{~mL}$ $=0.053$ inci hujan atau setara $1.346 \mathrm{~mm}$ hujan. Dalam $10 \mathrm{kali}$ percobaan tidak ditemukan error dalam penghitungan. Menu-

Tabel III. Pengujian sensor

\begin{tabular}{lll}
\hline Tip & Value & Galat \\
\hline 1 & 1.346 & $0 \%$ \\
2 & 2.692 & $0 \%$ \\
3 & 4.038 & $0 \%$ \\
4 & 5.384 & $0 \%$ \\
5 & 6.73 & $0 \%$ \\
6 & 8.076 & $0 \%$ \\
7 & 9.422 & $0 \%$ \\
8 & 10.768 & $0 \%$ \\
9 & 12.114 & $0 \%$ \\
10 & 13.46 & $0 \%$ \\
\hline
\end{tabular}

rut data dari Badan Meteorologi, Klimatologi, dan Geofisika (BMKG) terdapat 4 kriteria curah hujan :

1) Curah hujan rendah, $0-100 \mathrm{~mm}$

2) Curah hujan menengah, $100-300 \mathrm{~mm}$

3) Curah hujan tinggi, $300-500 \mathrm{~mm}$

4) Curah hujan sangat tinggi, diatas $500 \mathrm{~mm}$

Dengan data tersebut penulis mengklasifikasi penghitungan pada program agar sesuai dengan data yang didapat dari Badan Meteorologi, Klimatologi, dan Geofisika (BMKG) sebagai acuan deteksi dini kekeringan yang di mana pada curah hujan rendah meningkatkan potensi kekeringan pada sektor pertanian. Pada Tabel IV dilakukan pengujian dengan hujan buatan sampai pengukuran sensor menyentuh angka di atas $500 \mathrm{~mm}$ dan klasifikasi curah hujan berjalan dengan semestinya dengan galat pengukuran yang rendah. 
Tabel IV. Pengujian klasifikasi curah hujan

\begin{tabular}{llrr}
\hline Curah Hujan $(\mathrm{mm})$ & Notifikasi & Galat Bawah & Galat Atas \\
\hline $0-99.64$ & rendah & $0 \%$ & $0.36 \%$ \\
$100.95-300.158$ & Menengah & $0.95 \%$ & $0.053 \%$ \\
$301.504-499.366$ & Tinggi & $0.501 \%$ & $0.1268 \%$ \\
$500.712-\infty$ & Sangat Tinggi & $0.1424 \%$ & - \\
\hline
\end{tabular}

Pada Tabel V dilakukan pengujian fungsi pada bot telegram dengan 10 kali percobaan, pada pengujian tersebut fungsi berjalan dengan persentase $100 \%$.

Tabel V. Fungsi bot telegram

\begin{tabular}{lcc}
\hline Command & Berhasil & Gagal \\
\hline /hujan & $\checkmark$ & - \\
/report & $\checkmark$ & - \\
/reset & $\checkmark$ & - \\
\hline
\end{tabular}

Pengujian notifikasi dilakukan dengan membuat notifikasi tiap 1 jam dengan waktu pengujian selama 12 jam. Pada pengujian tersebut didapat akurasi notifikasi dengan persentase $100 \%$ seperti terlihat pada Gambar 14. Pengujian penyimpanan data

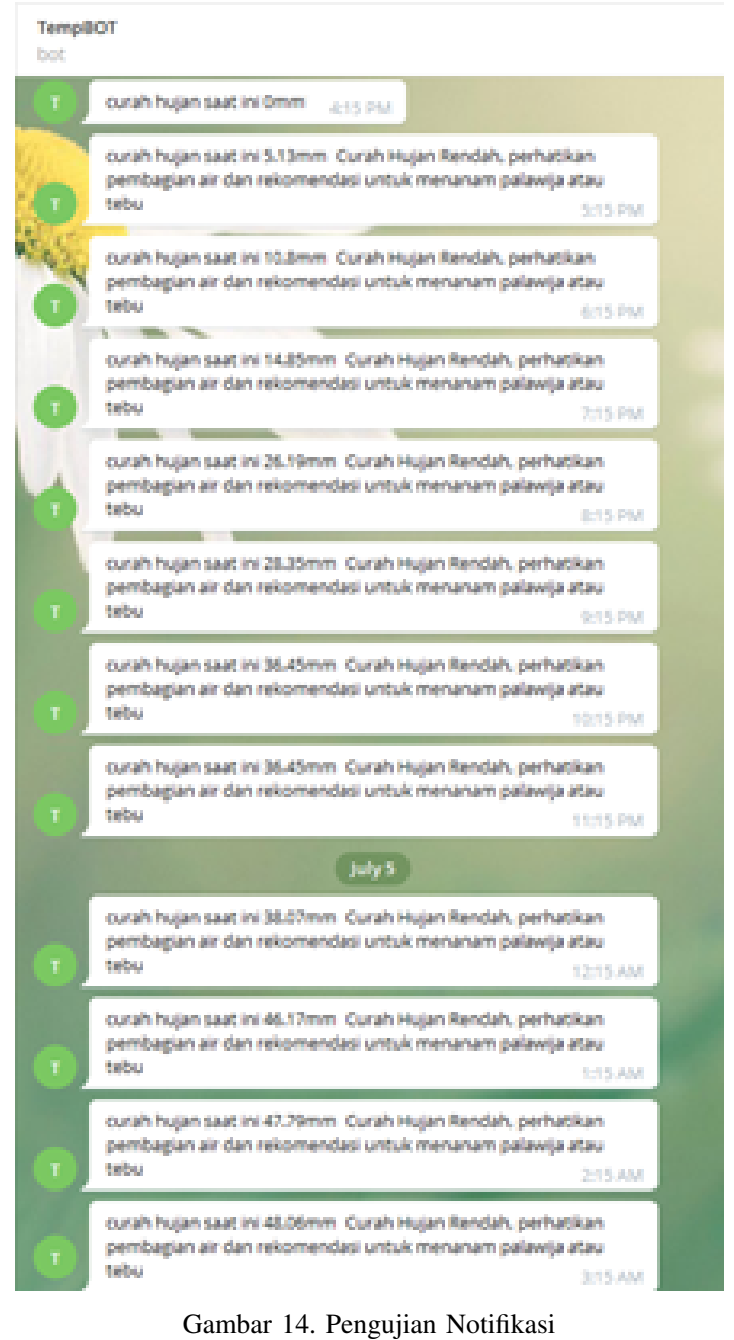

dilakukan dengan 10 kali percobaan dengan interval penyim-
Tabel VI. Penyimpanan data

\begin{tabular}{|c|c|c|c|}
\hline DATETIME & VALUE & BERHASIL & GAGAL \\
\hline $7 / 21 / 201916: 16$ & 0 & $\checkmark$ & - \\
\hline $7 / 21 / 201916: 22$ & 301.504 & $\checkmark$ & - \\
\hline $7 / 21 / 201916: 27$ & 639.35 & $\checkmark$ & - \\
\hline $7 / 21 / 201916: 32$ & 639.35 & $\checkmark$ & - \\
\hline $7 / 21 / 201916: 37$ & 639.35 & $\checkmark$ & - \\
\hline $7 / 21 / 201916: 42$ & 639.35 & $\checkmark$ & - \\
\hline $7 / 21 / 201916: 47$ & 639.35 & $\checkmark$ & - \\
\hline $7 / 21 / 201916: 52$ & 639.35 & $\checkmark$ & - \\
\hline $7 / 21 / 2019 \quad 16: 57$ & 639.35 & $\checkmark$ & - \\
\hline $7 / 21 / 2019$ 17:02 & 639.35 & $\checkmark$ & - \\
\hline
\end{tabular}

panan data setiap 5 menit. Pada Tabel VI fungsi penyimpanan data berjalan dengan semestinya.

\section{KESIMPULAN}

Mengacu pada hasil penelitian yang dilakukan sistem pengukur curah hujan sebagai deteksi dini kekeringan pada pertanian berbasis Internet Of Things (IOT) dapat berjalan sesuai dengan fungsinya, di mana alat dapat mengukur curah hujan dan memberi informasi dalam bentuk notifikasi peringatan dini potensi kekeringan pada sektor pertanian, yang diharapkan dapat meningkatkan produktivitas pada sektor pertanian. Penulis menyarankan untuk ke depannya sistem ini tidak hanya diterapkan pada sektor pertanian saja dan dapat dikembangkan untuk penerapannya pada sektor - sektor lain.

\section{DAFTAR PUSTAKa}

[1] I. N. Hidayati dan S. Suryanto, "Pengaruh perubahan iklim terhadap produksi pertanian dan strategi adaptasi pada lahan rawan kekeringan," JESP - Jurnal Ekonomi \& Studi Pembangunan, vol. 16, no. 1, April 2015.

[2] S. Evdokimov, B. Fabian, O. Günther, L. Ivantysynova, dan H. Ziekow, "Rfid and the internet of things: Technology, applications, and security challenges," Information and Operations Management, vol. 4, pp. 105185, 012010.

[3] L. N. Gunawan, J. Anjarwirawan, dan A. Handojo, "Aplikasi bot telegram untuk media informasi perkuliahan program studi informatika-sistem informasi bisnis universitas kristen petra," JURNAL INFRA, vol. 6, no. 1, 2018.

[4] M. A. Putra, "Rancang bangun alat pengukur curah hujan tipe tipping bucket otomatis berbasis mikrokontroler arduino mega 2560 dan internet of things (iot)," " 2017.

[5] K. Adawadkar, "Python programming-applications and future," International Journal of Advance Engineering and Research Development, 2017.

[6] M Kusban, B Hari P, and A Budiman. Palmprint recognition using the cosine method. IOP Conference Series: Materials Science and Engineering, 674:012041, nov 2019.

[7] Muhammad Kusban, Aris Budiman, and P. Bambang Hari. Optimized palmprint recognition with gabor parameters adjustment and matching method selection. Advanced Science Letters, 24(12), 2018.

[8] Muhammad Kusban, Aris Budiman, and Bambang Hari P. An excellent system in palmprint recognition. IOP Conference Series: Materials Science and Engineering, 403:012037, oct 2018.

[9] Muhammad Kusban, A. Susanto, and O. Wahyunggoro. Excellent performance of palmprint recognition by using wavelet filter. ICIC Express Letters, 11:1315-1321, 082017.

[10] Muhammad Kusban, Adhi Susanto, and Oyas Wahyunggoro. Combination a skeleton filter and reduction dimension of kernel pca based on palmprint recognition. International Journal of Electrical and Computer Engineering (IJECE), 6:3255-3261, 122016.

[11] M. Kusban, A. Susanto, and O. Wahyunggoro. Feature extraction for palmprint recognition using kernel-pca with modification in gabor parameters. In 2016 1st International Conference on Biomedical Engineering (IBIOMED), pages 1-6, 2016. 